\title{
Clinical inertia in type 2 diabetes: A retrospective analysis of pharmacist-managed diabetes care vs. usual medical care
}

Felix K. YAM, Aimee G. ADAMS, Holly DIVINE, Douglas STEINKE, Mikael D. JONES. Received (first version): 25-Jun-2013 Accepted: 13-Oct-2013

\begin{abstract}
${ }^{*}$
Background: Evidence suggests that patients with type 2 diabetes (T2DM) suffer from a high rate of "clinical inertia" or "recognition of the problem but failure to act."

Objective: The aim of this study is to quantify the rate of clinical inertia between two models of care: Pharmacist-Managed Diabetes Clinic (PMDC) vs. Usual Medical Care (UMC).

Methods: Patients in a university based medical clinic with type 2 diabetes (T2DM) were analyzed in this retrospective cohort study. Patients were exposed to either PMDC or UMC. The difference in days to intervention in response to suboptimal laboratory values and time to achieve goal hemoglobin A1c (A1C), systolic blood pressure (SBP) and low-density lipoprotein (LDL) was compared in the two models of care.

Results: A total of 113 patients were included in the analysis of this study, 54 patients were in the PMDC and 59 patients were in the UMC group. Median time (days) to intervention for $\mathrm{A} 1 \mathrm{c}$ values $>7 \%$ was 8 days and 9 days in the PMDC and UMC groups, respectively $(p>0.05)$. In patients with baseline A1c values $>8 \%$, median time to achieving $A 1 c<7 \%$ was 259 days vs. 403 days in the PMDC and UMC groups, respectively $(p<0.05)$. Median time to goal SBP was 124 days in the PMDC group and 532 days in the UMC group $(p<0.05)$. Median time to goal LDL was 412 days in the PMDC group vs. 506 days in the UMC group $(p<0.05)$.

Conclusions: Rates of clinical inertia, defined as time to intervention of suboptimal clinical values, did not differ significantly between patients enrolled in a PMDC compared to patients with UMC with respect to A1c, SBP and LDL. Participation in PMDC,
\end{abstract}

\footnotetext{
*Felix K. YAM. Pharm.D., MAS, BCPS. Assistant Clinical Professor. UCSD Skaggs School of Pharmacy and Pharmaceutical Sciences, University of California, San Diego. La Jolla, CA (United States). fyam@ucsd.edu Aimee G. ADAMS. Pharm.D. Adjunct Assistant Professor College of Pharmacy, University of Kentucky. Lexington, KY (United States). argelh1@email.uky.edu Holly DIVINE. Pharm.D, BCACP, CGP, CDE, FAPhA. Clinical Associate Professor. College of Pharmacy, University of Kentucky. Lexington, KY (United States). hsdivi1@email.uky.edu

Douglas STEINKE. BS Pharm, Ph.D. Senior Lecturer of Pharmacoepidemiology. Manchester Pharmacy School, University of Manchester. Manchester (United Kingdom). douglas.steinke@manchester.ac.uk

Mikael D. JONES. Pharm.D. BCPS. Clinical Associate Professor. College of Pharmacy, University of Kentucky. Lexington, KY (United States).mjone5@email.uky.edu
}

however, was associated with achieving goal A1C SBP, and LDL levels sooner compared to UMC.

Keywords: Diabetes Mellitus, Type 2; Pharmaceutical Services; Efficiency; Delivery of Health Care; United States

\section{INERCIA CLÍNICA EN DIABETES TIPO 2: ANÁLISIS RETROSPECTIVO DE CUIDADOS DIABÉTICOS POR FARMACÉUTICOS CONTRA CUIDADOS MÉDICOS HABITUALES}

\section{RESUMEN}

Antecedentes: La evidencia sugiere que los pacientes con diabetes tipo 2 (T2DM) padecen elevada "inercia clínica" o "reconocimiento del problema pero fracaso en la actuación".

Objetivo: El objetivo de este estudio es cuantificar la tasa de inercia clínica entre dos modelos de cuidados: consulta de diabetes gestionada por farmacéutico (PMDC) vs. cuidados médicos habituales (UMC).

Métodos: Se analizó en este estudio de cohorte retrospectiva a los pacientes con diabetes tipo 2 de una clínica médica universitaria. Los pacientes estuvieron expuestos a PMDC o a UMC. Se comparó la diferencia entro los dos modelos de cuidados en días desde la intervención en la respuesta a los valores sub-óptimos de laboratorio y el tiempo en alcanzar los objetivos de hemoglobina A1c (A1c) presión arterial sistólica (SBP) y lipoproteínas de baja densidad (LDL).

Resultados: Se incluyó en el análisis de este estudio a un total de 113 pacientes, 54 en el grupo PMDC y 59 en el UMC. La mediana de tiempo (días) desde la intervención para valores de A1c $>7 \%$ fue de 8 y 9 días en los grupos PMDC y $\mathrm{UMC}$, respectivamente $(\mathrm{p}>0,05)$. En los pacientes con $\mathrm{A} 1 \mathrm{c}$ basal $>8 \%$, la mediana de tiempo para alcanzar una $\mathrm{A} 1 \mathrm{c}<7 \%$ fue de 259 días vs. 403 días en los grupos PMDC y UMC, respectivamente $(p<0,05)$. El tiempo medio hasta el objetivo de SBP fue de 124 días en el grupo PMDC y 532 en el UMC $(p<0,05)$. La mediana de tiempo para el objetivo de LDL fue de 412 días en el grupo PMDC vs. 506 días en el UMC $(p<0,05)$.

Conclusiones: Las tasas de inercia clínica, definidos como el tiempo desde la intervención de valores clínicos sub-óptimos, no difirieron significativamente entre los pacientes incluidos en un PMDC comparados con pacientes en UMC en relación a A1c, SBP y LDL. Sin embargo, la participación en un PMDC estuvo asociado con 
alcanzar el objetivo de niveles de A1c, SBP y LDL más rápido, comparado con el UMC.

Palabras clave: Diabetes Mellitus, Tipo 2; Servicios Farmacéuticos; Eficiencia; Prestación de Atención de Salud; Estados Unidos

\section{INTRODUCTION}

Intensification of therapy in a timely manner and compliance with evidence based standards of care in patients with type 2 diabetes (T2DM) remains suboptimal despite strong clinical evidence that continues to support reduction in both macrovascular and microvascular damage in diabetes patients with optimal glycemic control. ${ }^{1}$ Despite recent conflicting data from the ACCORD (Action to Control Cardiovascular Risk in Diabetes) study $^{2}$, evidence still suggests that patients continue to derive benefit from intensive glycemic control, particularly in the early course of disease progression, prior to development of comorbidities. ${ }^{3} \quad$ Current American Diabetes Association (ADA) guidelines recommend targeting pre-prandial plasma glucose $90-130 \mathrm{mg} / \mathrm{dL}$, postprandial plasma glucose $<180 \mathrm{mg} / \mathrm{dL}$ and glycosylated hemoglobin (A1C) $<7 \%$. ${ }^{4}$ Guidelines from the American College of Endocrinology (ACE) target even lower goals in select patients: preprandial glucose less than $110 \mathrm{mg} / \mathrm{dL}$, postprandial glucose $<140 \mathrm{mg} / \mathrm{dL}$ and A1c $<6.5 \% .^{5}$ Despite wellestablished therapeutic goals, treatment of T2DM continues to fall short.

In an effort to improve care and achieve glycemic goals in patients with T2DM, researchers have sought to identify characteristics of primary care models that contribute to lack of optimization and failure to achieve treatment targets in patients with chronic disease. Clinical inertia is a term used to describe the current lack of timely intervention and treating to targets among patients with chronic disease states. Phillips and colleagues define clinical inertia as "recognition of the problem, but failure to act". 6 By this definition, clinical inertia is not a patient-centered problem but a problem of the health care system. A recent study evaluated primary care and specialist care in an attempt to characterize clinical inertia in each cohort of patients. ${ }^{7}$ The results of this trial revealed that less than $50 \%$ of patients in both groups had drug intensification in response to suboptimal $A 1 c$ values $(\mathrm{A} 1 \mathrm{c}>8 \%)$

Studies have quantified the rate of clinical inertia in several different practice settings to include academic medical centers and Veterans Affairs (VA) hospitals. ${ }^{8}$ Grant and colleagues recently demonstrated low rates of medical regimen change among a consortium of academic medical centers across the United States. The incidence of medication optimization in patients with A1c above goal was approximately $40 \%$. Rates of optimization remained less than $50 \%$ even among patients who had reported A1c's of $>9 \%$. Among untreated patients, few with elevated blood pressure $(10.1 \%$ with blood pressure $>130 / 80 \mathrm{mmHg}$ ) or elevated
LDL cholesterol $(5.6 \%$ with LDL $>100 \mathrm{mg} / \mathrm{dL})$ were initiated on therapy.

While the rate of clinical inertia has been published, no studies have quantified clinical inertia as a function of time. In this study we sought to quantify clinical inertia as a function of time and compare clinical inertia between two different models of care, a usual medical care model (UMC) and a pharmacist-managed diabetes clinic (PMDC), which was centered on dedicated patient visits with a Pharmacist in addition to the usual medical care a patient would normally receive. Collaborative care models with Pharmacists have demonstrated improved outcomes in patients with chronic diseases, such as diabetes.,10 Johnson and colleagues demonstrated a mean $\mathrm{A} 1 \mathrm{c}$ reduction of $3.6 \%$, in patients with baseline A1c $>10 \%$, who were enrolled in a pharmacist-based diabetes clinic. $^{11}$ We hypothesized that these improved outcomes could be attributed to a difference in clinical inertia or time to intervention of suboptimal A1c values.

\section{METHODS}

A retrospective cohort analysis was performed in patients who were a part of a university-based primary care clinic. These patients were separated into two cohorts depending on their exposure to usual medical care (UMC) or a pharmacistmanaged diabetes clinic (PMDC). Details of this pharmacist-managed diabetes clinic have been published elsewhere. ${ }^{12}$ But briefly, the PMDC program consists of patients referred by their primary care providers who attend a 1-hour individual assessment and then group diabetes education classes that follow the ADArecommended curricula. After completion of the classes, patients follow-up with a pharmacist every one to three months for medication therapy management and education reinforcement. In individual sessions, medication adherence, medication changes, behavioral goals, ADA standards of care, vital signs, weight, disease complications, primary care provider-ordered laboratory values, and self-monitoring of glucose results are assessed. Sensory monofilament exams and point-of-care hemoglobin A1c and lipid panels are performed when appropriate.

At the time of this study, pharmacists in this clinic did not have the authority to prescribe or adjust medication therapy. Instead, each visit with the pharmacist was summarized and documentation was sent along with any recommendations for improved disease management to the patient's health care providers. Patients who were a part of the PMDC also kept routine appointments with their primary care providers, who were aware that they were part of a pharmacist-managed diabetes clinic. Pharmacist recommendations from diabetes visits were flagged on the medical record for review during each patient visit with his or her primary care physician.

All study patients had a diagnosis of T2DM, were greater than 17 years of age at time of diagnosis, 
and received care by one of two practice models, pharmacist-managed diabetes clinic (PMDC) or usual medical care (UMC). Patients in the PMDC were included if they attended the initial assessments, three education classes and at least two visits to the PMDC. Inclusion criteria also included having at least three primary outcome measures (A1c) in the time period measured, between March 2003 and December 2005. These patients were identified using the PMDC patient database.

Usual medical care (UMC) patients were included in the analysis if they were diagnosed as incident T2DM patients between January $1^{\text {st }} 2000$ and June $30^{\text {th }} 2005$. Incident patients did not have a diagnosis of diabetes or a prescription for any anti-diabetic medication in the six months prior to diagnosis. Inclusion criteria for the UMC group included: data supporting that the diagnosis and treatment decisions were made by a primary care practitioner in the study clinic, at least two visits to the study clinic, at least three primary outcome measures (A1c) in the time period, and lack of enrollment in the PMDC program. Patients were identified from the university healthcare plan database using the primary diagnosis code as the reason for the visit (ICD-9 code of 250.xx (Diabetes Mellitus).

In each cohort, data was collected using standardized chart review forms for the study period and entered into the research database. For the UMC group, data from chart review included the dates January 2000 through December 2005. Data for the PMDC group included only data from the medical record and did not include PMDC clinic chart data. This was done to assess the effectiveness of using chart notes to communicate information between clinics. A clinic visit was defined as a visit to a physician, nurse practitioner, or pharmacist. The following variables were assessed: any A1c, lipid panel, recorded blood pressure measurement and diabetes-related intervention during the defined study period. An intervention was defined as the documented performance of any of the following: intensification of medication, addition of medication, diet/exercise counseling, medication counseling, referral, or disease state management education.

\section{Statistical Analysis}

The primary outcome in this study was time to intervention (days) for suboptimal A1c levels (>7\%). For each suboptimal laboratory value, the number of days between reporting of laboratory value and documented intervention in the patients' medical record was recorded. For each of the three diabetes-related risk factors: A1c, systolic blood pressure (SBP), low-density lipoprotein (LDL), the changes in corresponding medical regimens throughout the course of the study period was recorded. Treatment goals were derived from evidence-based national standards published by the American Diabetes Association (ADA). Additionally, medication change rates were stratified at different thresholds for A1c (>8\%), SBP $(>130 \mathrm{mmHg})$ and LDL (>130 mg/dL).
Chi-square and Fisher's exact tests were used to compare categorical data between groups as appropriate. Other continuous data were compared using Student's t-tests and Wilcoxon rank sum tests as appropriate. The primary endpoint of interest is the time to interventions. To compare the difference in days to endpoint between UMC and PMDC groups, Kaplan-Meier curves were created for the probability of achieving goal A1c, goal LDL and goal SBP over time. An estimated hazard ratio was calculated with a $95 \%$ confidence interval using the Cox proportional hazard regression in order to summarize the effect of type of care given on time to intervention. STATA version 11.1 (StataCorp, College Station, TX, USA) was used for all analyses and $\mathrm{P}<0.05$ was taken to indicate statistical significance.

\section{RESULTS}

A total of 120 patients were identified from the PMDC database that had T2DM and were actively enrolled in the pharmacist-managed diabetes clinic program. From this population, 54 (45\%) patients met inclusion criteria for the PMDC cohort. In the UMC group, 1300 patients with a diagnosis of diabetes were identified, of which 59 (4.5\%) patients met inclusion criteria for the control group. There were 1,241 patients excluded during data abstraction because chart information showed they had long-standing diabetes or A1c data was insufficient to be included in the study. Table 1 summarizes the demographic information, baseline medications and baseline A1c groupings for each cohort. Baseline A1c values were not statistically different between groups.

Table 2 summarizes the analysis of A1c values. Among those A1c values that were not at goal, 55\% prompted intervention in the PMDC group compared to $52 \%$ in the UMC group $(p>0.05)$. Compared to the UMC group, the PMDC group did

\begin{tabular}{|c|c|c|}
\hline Total population (n, \%) & $\begin{array}{l}\text { PMDC } \\
(n=54)\end{array}$ & $\begin{array}{c}\text { UMC } \\
(n=59)\end{array}$ \\
\hline $\begin{array}{r}\text { Female } \\
\text { Male }\end{array}$ & $\begin{array}{l}35(64.8) \\
19(35.2)\end{array}$ & $\begin{array}{l}22(37.3) \\
37(62.7)\end{array}$ \\
\hline Mean age (SD)* & $50.1(10.1)$ & $44.1(9.4)$ \\
\hline $\begin{array}{r}\text { Asian } \\
\text { African-American } \\
\text { Caucasian } \\
\text { Other }\end{array}$ & $\begin{aligned} 2 & (3.7) \\
13 & (24.1) \\
37 & (68.5) \\
2 & (3.7)\end{aligned}$ & $\begin{aligned} 2 & (3.5) \\
12 & (20.6) \\
40 & (69.0) \\
4 & (6.9)\end{aligned}$ \\
\hline $\begin{array}{r}\text { Diabetes Therapy } \\
\text { Diet and Exercise Only* } \\
\text { Monotherapy Oral } \\
\text { Combination Oral } \\
\text { Combination Oral Insulin* }\end{array}$ & $\begin{array}{c}2(3.7) \\
22(40.7) \\
23(42.6) \\
6(11.1) \\
\end{array}$ & $\begin{array}{c}12(20.3) \\
27(45.8) \\
19(32.2) \\
0 \\
\end{array}$ \\
\hline $\begin{array}{r}<7 \% \\
7-7.9 \% \\
8-8.9 \% \\
>9 \%\end{array}$ & $\begin{array}{c}32(59.2) \\
8(14.8) \\
3(5.6) \\
11(20.4)\end{array}$ & $\begin{array}{l}29(49.2) \\
15(25.4) \\
7(11.8) \\
8(13.6)\end{array}$ \\
\hline $\begin{array}{r}\text { Grouping from initial systolic BP } \\
<130 \mathrm{mmHg} \\
130-159.9 \mathrm{mmHg} \\
\geq 160 \mathrm{mmHg}\end{array}$ & $\begin{array}{c}18(40.9) \\
24(54.6) \\
2(4.5)\end{array}$ & $\begin{array}{c}15(25.9) \\
36(62.1) \\
7(12.0)\end{array}$ \\
\hline
\end{tabular}




\begin{tabular}{|c|c|c|}
\hline Variable & PMDC & UMC \\
\hline Number of $A 1 \mathrm{c}$ values $\geq 7 \%$ & 148 & 194 \\
\hline Of these, how many had an interventions & $83(56)$ & $101(52)$ \\
\hline Median number of days to intervention & $8(1-475)$ & $9(1-372)$ \\
\hline Median days to intervention by $\mathrm{A} 1 \mathrm{C}$ range & $\begin{array}{c}8(1-475) \\
7(3-251) \\
22(2-363)\end{array}$ & $\begin{array}{c}7(1-293) \\
29(2-372) \\
25(1-225)\end{array}$ \\
\hline 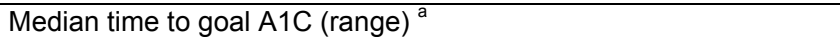 & $227(99-1362)$ & $250(20-1778)$ \\
\hline Median time to goal by initial $\mathrm{A} 1 \mathrm{C}$ group & $\begin{array}{c}329(99-1362) \\
259(99-960)\end{array}$ & $\begin{array}{c}195(2-941) \\
403(31-1778)\end{array}$ \\
\hline
\end{tabular}

not differ in clinical inertia or median days to intervention in response to a suboptimal lab value $(p>0.05)$. The overall median time to goal relative to initial A1c groupings also did not differ in the PMDC group compared with the UMC group, 227 days vs. 250 days $(p>0.05)$, respectively. In patients with baseline A1c>8\%, patients in the PMDC group who achieved goal $A 1 c<7 \%$ did so by a median of 144 days sooner $(p<0.05)$. Kaplan-Meier survival analysis used to assess the probability of patients achieving goal A1c over time did not reveal any overall differences between groups, hazard ratio, $1.00(95 \% \mathrm{Cl}, 0.99-1.00)$ (Figure 1). When isolating only those patients that begin the study at $A 1 \mathrm{c}>=8$, the Cox regression was still not significant (HR 0.80, $95 \% \mathrm{Cl} 0.18-3.51 ; \mathrm{p}=0.766$ ).

Systolic blood pressure (SBP) and LDL were also assessed in both study populations. These results are summarized in Tables 3 and 4 . Patients in both groups had low rates of medication intervention (addition or dose optimization) in response to SBP readings not at goal, $8 \%$ and $18 \%$, in the PMDC group vs. UMC, respectively. Due to inconsistent documentation of intervention in response to elevated blood pressure readings, we were unable to report median days to intervention in response to SBP readings. Patients in the PMDC group who reached goal SBP $(<130 \mathrm{~mm} \mathrm{Hg})$, however, did so by a median of 408 days sooner compared to UMC patients who reached goal SBP $(p<0.05)$. When compared with patients in the UMC group, patients in the PMDC group also had a higher probability of achieving goal SBP $(<130 \mathrm{~mm} \mathrm{Hg})$ earlier in the course of therapy although this hazard ratio did not reach statistical significance $(\mathrm{HR} 2.21,95 \% \mathrm{Cl} 0.63-$ 7.76) (Figure 2).

In comparison to $\mathrm{A} 1 \mathrm{c}$ and SBP interventions, higher rates of intervention were seen in response to elevated LDL-C levels, $13 \%$ of patients in the PMDC group and $16 \%$ in the UMC group. Median time to intervention for LDL levels above goal did not differ between the two groups $(p>0.05)$. However, in patients who achieved goal LDL, median time to goal (days) was significantly shorter in the PMDC group (412 days vs. 506 days, $\mathrm{p}<0.05)$. The Kaplan-Meier curve shows no difference in probability of achieving goal over time between the two groups (HR $0.7395 \% \mathrm{Cl} 0.25-2.13$ ) (Figure 3).

\section{DISCUSSION}

This is the first study to our knowledge that quantifies the rate of clinical inertia by measuring the number of days between obtaining suboptimal clinical values and subsequent intervention. Furthermore, we chose to characterize clinical inertia among two different models of care in order to provide an additional explanation for improved outcomes associated with pharmacist-based collaborative care models., ${ }^{9,11,13}$ We found no difference in time to intervention of suboptimal A1c values between PMDC and UMC. When patients with baseline A1c values $>8 \%$ were analyzed, however, patients in the PMDC group had significantly shorter time to achieving goal compared to the UMC group.

The data demonstrated that patients who have a higher baseline A1c benefited from early, intensive pharmacist-based diabetes intervention. These findings also suggest that other factors besides clinical inertia are responsible for the significant reductions in $\mathrm{A} 1 \mathrm{C}$ and other diabetes related risk factors (SBP and LDL) that have been reported with this pharmacist-managed diabetes clinic program. ${ }^{11}$ The original hypothesis proposed that lower rates of clinical inertia in the PMDC group would explain

\begin{tabular}{|c|c|c|}
\hline Variable $(n, \%)$ & PMDC & UMC \\
\hline Total population $(n=102)$ & 44 & 58 \\
\hline Number of systolic BP values $\geq 130$ & 327 & 572 \\
\hline $\begin{array}{r}\text { Dose optimization* } \\
\text { Add a drug* } \\
\text { Patient education* }\end{array}$ & $\begin{array}{l}16(4.9) \\
11(3.4) \\
5(1.5)\end{array}$ & $\begin{array}{c}53(9.3) \\
49(8.6) \\
30(13.4)\end{array}$ \\
\hline Median time (days) to intervention & $\begin{array}{c}\text { Data not consistently reported on } \\
\text { date on when intervention occurred }\end{array}$ & \\
\hline Number of patients reaching goal systolic ${ }^{d}$ & 9 & 23 \\
\hline Median time (days) to goal (range) ${ }^{* d}$ & $124(35-947)$ & $532(31-1778)$ \\
\hline
\end{tabular}




\begin{tabular}{|c|c|c|}
\hline Variable $(n, \%)$ & PMDC & UMC \\
\hline Total population $(\mathrm{N}=77)$ & 27 & 50 \\
\hline \multicolumn{3}{|l|}{ Grouping from initial LDL } \\
\hline$<70$ & $2(7)$ & $6(12)$ \\
\hline 70-99.9 & $10(37)$ & $13(26)$ \\
\hline $100-129.9$ & $9(33)$ & $10(20)$ \\
\hline $130-159.9$ & $4(15)$ & $18(36)$ \\
\hline$\geq 160$ & $2(7)$ & $3(56)$ \\
\hline $\begin{array}{l}\text { Number of lab values with } \\
\text { LDL } \geq 100\end{array}$ & 127 & 164 \\
\hline Interventions performed & & \\
\hline Dose optimization & $7(5.5)$ & $6(3.7)$ \\
\hline Add a drug & $9(7.1)$ & $21(12.8)$ \\
\hline Patient education* & $1(0.8)$ & $27(16.5)$ \\
\hline $\begin{array}{l}\text { Median time (days) to } \\
\text { intervention }\end{array}$ & $7(1-322)$ & $8(1-343)$ \\
\hline $\begin{array}{l}\text { Number of patients reaching goal } \\
\operatorname{LDL}^{f}\end{array}$ & 12 & 20 \\
\hline $\begin{array}{l}\text { Median time (days) to goal } \\
\text { (range) }{ }^{*}\end{array}$ & $\begin{array}{c}412 \\
(119-553) \\
\end{array}$ & $\begin{array}{c}506 \\
(77-1508) \\
\end{array}$ \\
\hline
\end{tabular}

improved outcomes. However, results from this trial demonstrated no difference in clinical inertia, yet significant differences were detected in the time to achieve goal, favoring patients in the PMDC group. This suggests that measuring time to achieving goal measures may be a better predictor of positive outcomes compared to time to intervention.

Results from the analysis of secondary outcomes in this study further support this theory. Patients in the PMDC group had a higher probability of achieving SBP goals when compared to UMC patients and shorter time (days) to achieving goal SBP and LDL levels when compared to UMC. Patients in the PMDC group achieved goal SBP nearly eight months sooner and achieved goal LDL over two months sooner compared to UMC patients. In the absence of differences in time to intervention, these improvements may be attributed to diabetes related education and reinforcement of disease state management through lifestyle modification and medication adherence. This finding further supports the impact of pharmacist-provided diabetes education on achieving ADA goals.

Although not specifically evaluated in our study, we

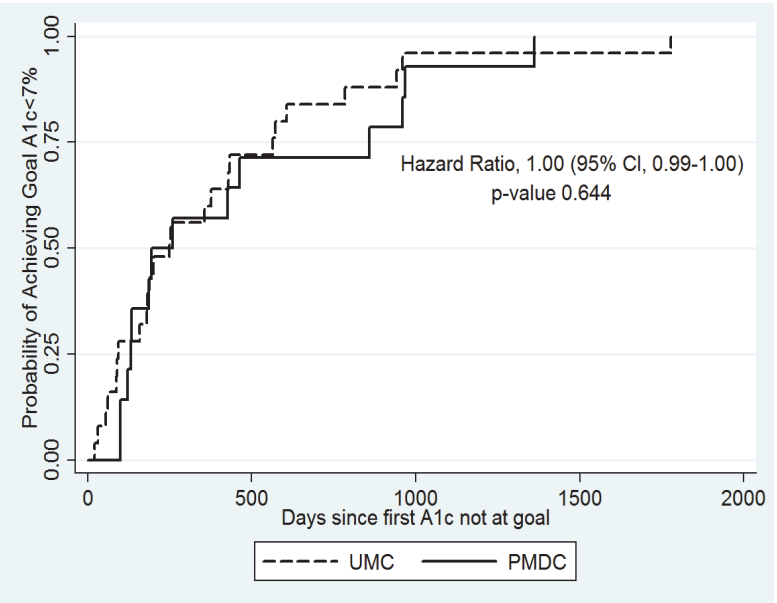

Figure 1. Kaplan-Meier curves for the probability of achieving goal A1C suspect that patients enrolled in the PMDC group had greater adherence to prescribed therapy and lifestyle interventions as a result of their participation in the pharmacist-managed diabetes program. These "treatment" or pharmacistintervention effects may have led to the findings of improved SBP and LDL outcomes seen in this study. Other studies have also demonstrated the link between pharmacist education, medication adherence and outcomes. ${ }^{14}$ The effects of these types of interventions are more detectable in nearterm and can be measured given the immediate effects of medication adherence and lifestyle modification on parameters such as blood pressure and lipid profile.

The PMDC program consisted of a combination of appropriate nutrition, physical activity and preventative screening. These factors are underscored through the promotion of diabetes selfmanagement, which is an ongoing, education process that included the following: 1) assessment of the individual's specific education needs; 2) identification of the individual's specific diabetes self-management goals; 3) education and behavioral intervention directed toward helping the individual achieve identified self-management goals; 4) evaluation of the individual's attainment of identified self-management goals. ${ }^{15}$ In a metaanalysis conducted by the Centers for Disease Control (CDC), patient self-management education was effective in improving outcomes in patients with diabetes. ${ }^{14}$ Results from our study corroborate with these findings.

This retrospective analysis identified systematic program issues that may have affected the results of this study. At the time of the study pharmacists in our program did not have the authority to adjust medications but they were aggressive in providing disease state education and medication counseling to improve medication adherence. Following each visit, a complete note with recommendations from the pharmacist was written and sent to the patients' primary care physician for review. In a separate published analysis of this PMDC, DeName and colleagues found that the median time of 2 weeks elapsed before the healthcare provider in this

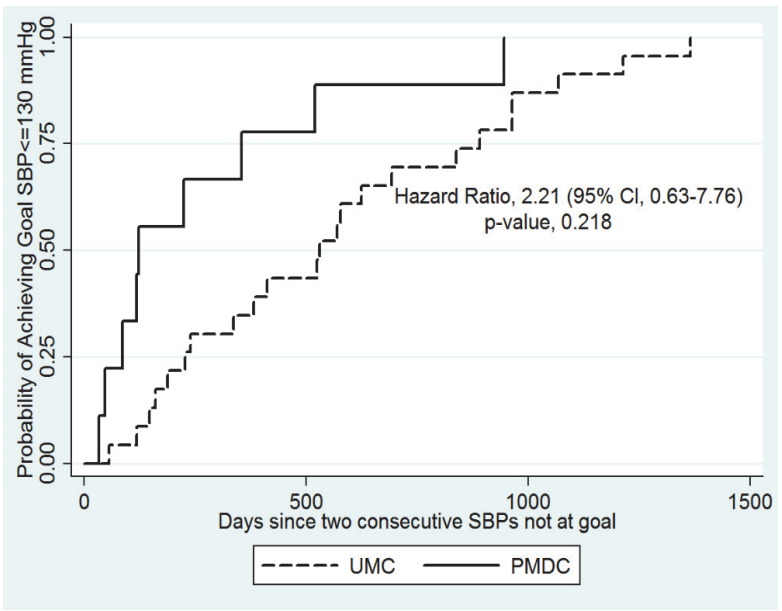

Figure 2. Kaplan-Meier curve for the probability of achieving Goal SBP 


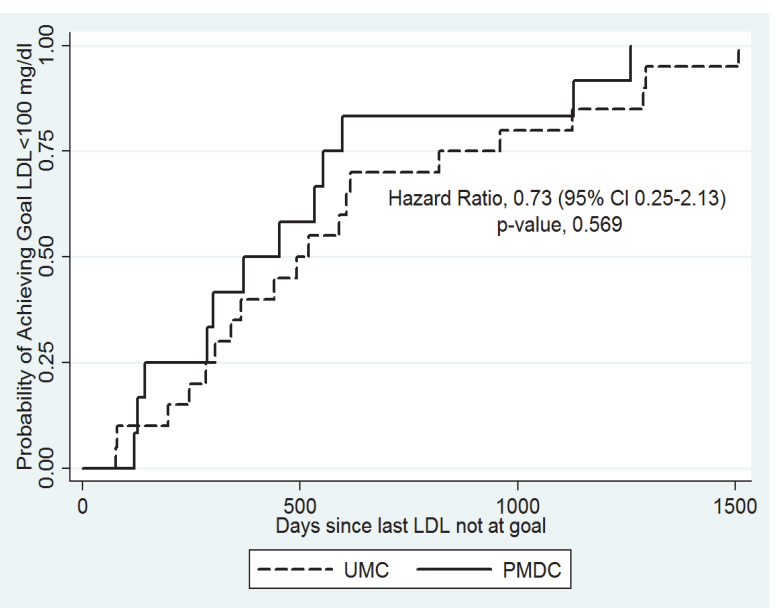

Figure 3. Kaplan-Meier curve for the probability of achieving goal LDL

practice setting accepted a clinical medication recommendation. ${ }^{16}$ Moreover, the acceptance rate of clinical recommendations made to the provider was $60.2 \%$. The inability to actively modify patient treatment regimens within the PMDC had an impact on clinical inertia as defined in our study and in some cases; this model may have contributed to clinical inertia.

In retrospect, if pharmacists had the ability to take action at the point of care, clinical inertia may have been significantly reduced based on the days lapsed between patient clinic visits with the pharmacist and the primary care provider. Although the time to medication optimization was not different between PMDC and UMC, patients in the PMDC group received instant feedback and education from pharmacists who helped motivate patients to achieve target goals. Findings from this study suggest that targeted patient education programs can improve outcomes in patients with diabetes, independent of the rates of medication optimization or time to intervention.

Another potential source of bias identified was the differences between patient groups identified at baseline. In an effort to reduce selection bias, we identified patients who were newly diagnosed in the UMC group in order to match the intensity of treatment patients received in the PMDC group. It was assumed that patients who were newly diagnosed were more likely to receive initial diabetes education, performance of ADA standards of care, and medication initiation compared to those patients who have long-standing diabetes. Selecting incident cases of T2DM in the UMC group may have led to an unfavorable comparison since patients in the PMDC group had long-standing T2DM and may have had long-standing issues with adherence to treatment or clinic visits that were not identified. This may have biased the results of the study towards not detecting a difference in time to intervention.

As a potential source of information bias, it should also be noted that the average time of enrollment for patients in the pharmacist-managed diabetes clinic group was 612 days or 1.7 years. The data for these patients were collected from their initial enrollment to their most recent clinic visit even though patients may have stopped being seen by the PMDC group. Patients had the option to disenroll from the program after meeting initial requirements. Following dis-enrollment, patients maintained their visits with their primary care provider in internal medicine. Data collection continued under the planned intention to treat analysis. As a result, these patients who were engaged with PMDC for a limited period of time would likely have less benefit from being a part of the program. Comparatively, patients in the UMC group had increased exposure time due to the average duration of follow-up, which was five years.

Despite these biases and the limitations inherent in retrospective analyses, this study demonstrates the impact of pharmacist-based diabetes management on improving outcomes in patients with T2DM. Clinical inertia and the rates of medication optimization in patients with T2DM should remain an important quality measure evaluated among organizations. Evidence still supports intensive early treatment of patients with new onset diabetes to limit disease progression and to slow the decline of beta cell function. ${ }^{17}$ Medication therapy is critical in this early stage to reduce insulin resistance and prevent the detrimental effects of prolonged hyperglycemia. Despite questionable support for intensive glycemic control to reduce macrovascular events, analysis of ACCORD data continues to demonstrate the benefit of intensive glycemic control in reducing microvascular event rates. ${ }^{2}$ These affects seem to be magnified when treating patients earlier in their course of disease and prior to developing additional co-morbidities.

This project expands upon the initial results of the PMDC program by identifying a link between improved outcomes and disease state management by pharmacists. Despite the inability to detect a significant difference in clinical inertia rates, significant improvements in outcomes were detected. Methods to counteract clinical inertia, however, are still needed to improve quality of care and ultimately outcomes related to diabetes. Pharmacists can play a pivotal role in improving the quality of care diabetes patients receive and counteracting clinical inertia through patient education. This can occur through structural and organizational changes in clinical practice that allow for early screening, detection and management of suboptimal diabetes control before the onset of morbidity and mortality related to diabetes.

Optimizing collaborative disease state management programs between pharmacists and providers remain essential to combating clinical inertia. The American Society of Health-System Pharmacists (ASHP) recently launched the Pharmacy Practice Model Initiative (PPMI), which seeks to redefine the way pharmacists practice within the health-system to provide direct patient care that maximizes their potential for impact. ${ }^{18}$ Results from this study further support this initiative in that it demonstrates the impact that regulatory and scope of practice limitations has on pharmacists' ability to act as direct care providers to improve patient outcomes. 
These limitations, which vary widely between states, can impact the effectiveness pharmacists have on reducing rates of clinical inertia.

\section{CONCLUSIONS}

Despite evidence demonstrating improved patient outcomes, a pharmacist-managed diabetes clinic model without authority to adjust medication therapy or order laboratory tests according to approved collaborative practice agreements, did not reduce clinical inertia or time to intervention of suboptimal laboratory values when compared to UMC. However, significant improvements in time to achieving goal A1c, SBP and LDL was detected in high-risk groups. Based on findings from this study, we suggest that pharmacist-managed diabetes clinics seek to obtain collaborative care agreements with their physician partners that allow for medication adjustments and ordering of routine laboratory tests. These agreements should be evidence based and mutually agreed upon with their supervising physician. Reducing clinical inertia in diabetes rests in the ability to make timely decisions and take immediate action when responding to patient clinical outcomes that are not at goal. Diabetes education continues to be an important tool in the treatment arsenal and should augment any strategy to reduce clinical inertia and improve patient outcomes. Further studies are needed to establish the impact of pharmacist-based diabetes management on patient adherence and outcomes.

\section{ACKNOWLEDGEMENTS}

This work was supported by the American Society of Health System Pharmacists Research Foundation.

\section{CONFLICT OF INTEREST}

None declared.

Funding: The authors would like to declare that funding for this project was obtained from ASHP Foundation through the Fostering Young Investigators Pharmacy Resident Health Services Grant.

\section{References}

1. UK Prospective Diabetes Study (UKPDS) Group. Intensive blood-glucose control with sulphonylureas or insulin compared with conventional treatment and risk of complications in patients with type 2 diabetes (UKPDS 33). Lancet. 1998;352(9131):837-853.

2. Action to Control Cardiovascular Risk in Diabetes Study Group, Gerstein HC, Miller ME, Byington RP, Goff DC Jr, Bigger JT, Buse JB, Cushman WC, Genuth S, Ismail-Beigi F, Grimm RH Jr, Probstfield JL, Simons-Morton DG, Friedewald WT. Effects of intensive glucose lowering in type 2 diabetes. N Engl J Med. 2008;358(24):2545-2559. doi: 10.1056/NEJMoa0802743

3. Greenfield S, Billimek J, Pellegrini F, Franciosi M, De Berardis G, Nicolucci A, Kaplan SH. Comorbidity affects the relationship between glycemic control and cardiovascular outcomes in diabetes: a cohort study. Ann Intern Med. 2009;151(12):854-860. doi: 10.7326/0003-4819-151-12-200912150-00005

4. American Diabetes Association. Standards of Medical Care in Diabetes--2013. Diabetes Care. 2013;36(Suppl 1):S11S66. doi: 10.2337/dc13-S011

5. Rodbard HW, Blonde L, Braithwaite SS, Brett EM, Cobin RH, Handelsman Y, Hellman R, Jellinger PS, Jovanovic LG, Levy P, Mechanick JI, Zangeneh F; AACE Diabetes Mellitus Clinical Practice Guidelines Task Force. American Association of Clinical Endocrinologists medical guidelines for clinical practice for the management of diabetes mellitus. Endocr Pract. 2007;13(Suppl 1):1-68.

6. Phillips LS, Branch WT, Cook CB, Doyle JP, El-Kebbi IM, Gallina DL, Miller CD, Ziemer DC, Barnes CS. Clinical inertia. Ann Intern Med. 2001;135(9):825-834.

7. Shah BR, Hux JE, Laupacis A, Zinman B, van Walraven C. Clinical inertia in response to inadequate glycemic control: do specialists differ from primary care physicians? Diabetes Care. 2005;28(3):600-606.

8. Grant RW, Buse JB, Meigs JB; University HealthSystem Consortium (UHC) Diabetes Benchmarking Project Team. Quality of diabetes care in U.S. academic medical centers: low rates of medical regimen change. Diabetes Care. 2005;28(2):337-442.

9. Cranor CW, Bunting BA, Christensen DB. The Asheville Project: long-term clinical and economic outcomes of a community pharmacy diabetes care program. J Am Pharm Assoc (Wash). 2003;43(2):173-184.

10. Cranor CW, Christensen DB. The Asheville Project: short-term outcomes of a community pharmacy diabetes care program. J Am Pharm Assoc (2003). 2003;43(2):149-159. doi: 10.1331/108658003321480696

11. Johnson CL, Nicholas A, Divine H, Perrier DG, Blumenschein K, Steinke DT. Outcomes from DiabetesCARE: a pharmacist-provided diabetes management service. J Am Pharm Assoc (2003). 2008;48(6):722-730. doi: 10.1331/JAPhA.2008.07133

12. Divine H, Nicholas A, Johnson CL, Perrier DG, Steinke DT, Blumenschein K. PharmacistCARE: description of a pharmacist care service and lessons learned along the way. J Am Pharm Assoc (2003). 2008;48(6):793-802. doi: 10.1331/JAPhA.2008.07132

13. Bodenheimer T, Wagner $\mathrm{EH}$, Grumbach $\mathrm{K}$. Improving primary care for patients with chronic illness: the chronic care model, Part 2. JAMA. 2002;288(15):1909-1914.

14. Norris SL, Engelgau MM, Narayan KM. Effectiveness of self-management training in type 2 diabetes: a systematic review of randomized controlled trials. Diabetes Care. 2001;24(3):561-587.

15. American Diabetes Association. Standards of medical care in diabetes. Diabetes Care. 2005;28(Suppl 1):S4-S36. 
16. DeName B, Divine H, Nicholas A, Steinke DT, Johnson CL. Identification of medication-related problems and health care provider acceptance of pharmacist recommendations in the DiabetesCARE program. J Am Pharm Assoc (2003). 2008;48(6):731-736. doi: 10.1331/JAPhA.2008.07070

17. The Diabetes Control and Complications Trial Research Group. The effect of intensive treatment of diabetes on the development and progression of long-term complications in insulin-dependent diabetes mellitus. N Engl J Med. 1993;329(14):977-986.

18. Zellmer WA, Cobaugh DJ, Chen D. Three signals from the Pharmacy Practice Model Summit. Am J Health Syst Pharm. 2011;68(12):1077. doi: 10.2146/ajhp110148 